\title{
Tailoring Natural Zeolites by Acid Treatments
}

\author{
Marcia Silva* ${ }^{(10}$, Alice Lecus, Yuting Lin, Joseph Corrao \\ Water Technology Accelerator (WaTA), University of Wisconsin-Milwaukee, Milwaukee, USA \\ Email: *msilva@uwm.edu
}

How to cite this paper: Silva, M., Lecus, A., Lin, Y.T. and Corrao, J. (2019) Tailoring Natural Zeolites by Acid Treatments. Journal of Materials Science and Chemical Engineering, 7, 26-37.

https://doi.org/10.4236/msce.2019.72003

Received: January 25, 2019

Accepted: February 25, 2019

Published: February 28, 2019

Copyright (C) 2019 by author(s) and Scientific Research Publishing Inc. This work is licensed under the Creative Commons Attribution International License (CC BY 4.0).

http://creativecommons.org/licenses/by/4.0/

\begin{abstract}
In this study, a comparison of a variety of existing acid treatment methods for zeolite based on their abilities to modify physical properties of the particles is performed. Evaluation of the effects that four different acids have on numerous properties of the zeolites including surface area, pore size, pore volume, thermal stability, IR spectra, crystallinity, and morphology is conducted and compared with the reference untreated zeolite. Furthermore, all five zeolite particles are evaluated for their adsorption properties in column mode experiments. The importance of the examined features is discussed. The results obtained in this work are compared to similar studies to examine which conditions greatly influence the zeolite modifications.
\end{abstract}

\section{Keywords}

Zeolites, Clinoptilolites, Acid Treatment, Physical Properties

\section{Introduction}

Zeolite, both naturally occurring and synthetically produced contains many unique properties. A majority of the naturally occurring material is formed through a combination of oceanic and volcanic processes over long periods of time. Zeolite forms a tetrahedral structure composed of alumina, silica, and other various metal cations [1]. Most of the zeolite composition is dominated by alumina and silica; the metal cations are found in much smaller quantities as they are predominantly found on the zeolite surface. These tetrahedral structures then arrange themselves into a greater network of channels and pores [2]. Several variations of these arrangements give rise to specified zeolite cage types that include; fujaste, sodalite, and type A.

Zeolites versatility as an adsorbent and molecular sieve provide industry with a powerful and environmentally friendly material. Since it contains acid sites and a large network of pores, it is extremely useful as a catalyst, for ion exchange, 
and the purification of water [3] [4] [5]. Most of the zeolite activity occurs at the cation sites on the surface, and for the greater interest of the water industry, is the location of cation exchange. While naturally occurring, the material provides a cost friendly alternative to the synthetically produced ones; there are many defects and imperfections found in the natural material. For this reason, understanding the characteristics of the surface in addition to the development of methods that further improve these features is crucial. Adsorbent porosity is an extremely important factor in wastewater treatment, because a more porous material indicates that there is greater volume and surface area for toxic pollutants to be adsorbed onto [3].

One successful method for modification involves the use of acid [6] [7] [8]. The impact of sulfuric acid treatments among many others has been examined in the past; however further research into additional variants of acid treatment needs to be explored to fully understand the potential of this modification method. Other acids researchers have investigated for zeolite treatment include: hydrochloric acid, nitric acid, acetic acid, just to name a few [9] [10]. Combination of multiple acids such as phosphoric acid with citric acid has also been studied [11]. One challenge was that not many studies that directly compared the impact of different acids and their influence on particle modification. The target of the acid treatment is to remove the aluminum from a natural zeolites aluminosilicate framework in order to create more void spaces (pores) within the material [12].

From what has already been found, the overall process of acid treating zeolite to enhance specific features has a great deal of complexity [8]. While not much has been reported on the comparison of zeolite type (e.g. clinoptilolite), one could not simply examine results from one type and draw the same conclusions for all other types. Another issue is that one could not explicitly conclude trends based on acid category without extensive testing on a wide range of acids. The process in which the zeolite is treated by acid plays a critical role as well including acid concentration, temperature, and treatment duration [13]. The intent for this paper is not to explain everything about the acid treatment process, but much rather to elucidate a small portion of a bigger picture. This paper seeks to identify acid treatments that substantially modify clinoptilolite in terms of surface area, pore size, and thermal stability. These targeted attributes are emphasized in the interest of developing a material that may be beneficial for applications in water industry.

\section{Materials and Methods}

The natural Australian clinoptilolite zeolite (diameter: $0.7-1 \mathrm{~mm}$, chemical composition: $68.26 \% \mathrm{SiO}_{2}, 12.99 \% \mathrm{Al}_{2} \mathrm{O}_{3}, 4.11 \% \mathrm{~K}_{2} \mathrm{O}, 2.09 \% \mathrm{CaO}, 1.37 \% \mathrm{Fe}_{2} \mathrm{O}_{3}$, $0.83 \% \mathrm{MgO}, 0.64 \% \mathrm{Na}_{2} \mathrm{O}, 0.23 \% \mathrm{TiO}_{2}$ ) provided by Zeolite Australia PTY Limited first treated with ultrasonication (Fisherbrand FB11201) and microwaving with a series of subsequent rinses using deionized (DI) water. 
After the material was cleaned by the removal of loose debris, it was dried in an oven at $100^{\circ} \mathrm{C}$ for 24 hours.

All acid treatments discussed in this paper refer to the modification of the dried, sonicated, and microwaved material (clean zeolite). Four different acids were used in this study including: sulfuric (KMG 96\% Sulfuric acid), hydrochloric (Hach concentrated ACS grade), nitric (Veritas 69\% redistilled), and acetic (Fisher Chemical 99.7\% HPLC Grade) acids. $20 \mathrm{~g}$ of clean zeolite was refluxed in a three-neck boiling flask with $115 \mathrm{~mL}$ of DI water and $10 \mathrm{~mL}$ of concentrated acid for 12 hours at approximately $90^{\circ} \mathrm{C}$. The concentrations for hydrochloric, sulfuric, nitric, and acetic acids are $0.97 \mathrm{M}, 1.43 \mathrm{M}, 1.25 \mathrm{M}$, and $1.39 \mathrm{M}$ respectively. The apparatus was closed off by a Vigreux column, a thermometer, and aluminum foil to help prevent excessive evaporation of water. After the material was treated for 12 hours it was rinsed with absolute ethanol (Fisher Chemical denatured) and then thoroughly with DI water. Once the rinsing was completed, the material was dried in an oven at $100^{\circ} \mathrm{C}$ for 24 hours.

Samples for FTIR analysis were ground into a fine powder before measurements were collected using a Shimadzu IR Tracer 100 with an ATR table. For all other measurements the samples were not ground into a powder. Surface area, pore volume and pore diameter were measured using a Quantachrome Autosorb IQ2 gas sorption analyzer. Samples were degassed at a final temperature of $350^{\circ} \mathrm{C}$ for approximately 17 hours and analyzed with nitrogen adsorptive at $77 \mathrm{~K}$. Thermal stability was examined via Differential Thermal Thermogravimetric (DTG) analyzer with a Shimadzu DTG-60 model using dry grade air flow in alumina pans up to a temperature of $600^{\circ} \mathrm{C}$. Samples for X-ray diffraction (XRD) analysis were carried out in a Bruker AXS D8 for 30 minutes from $2 \theta=10^{\circ}$ to $80^{\circ}$ at $40 \mathrm{kV}$ using a Cu tube (1.5418 $\left.\mathrm{A}\right)$. The morphology and composition of the zeolite particles were characterized using a Hitachi S-4800 field emission scanning electron microscope (FESEM). Samples were mounted on SEM stubs which were coated with $5 \mathrm{~nm}$ of iridium and viewed at an accelerating voltage of $10 \mathrm{kV}$

Evaluation of the adsorption properties of the zeolite particles were performed in column mode experiments with a weakly cationic model compound Disperse Blue 26 (DB 26) (Crescent Chemical, ASC12972019). A column setup was utilized and were conducted in glass columns (length $=21 \mathrm{~cm}$ and internal diameter $=2 \mathrm{~cm}$ ). A piece of gauze was placed at the bottom of the column and the zeolite was added to the column to a height of $13 \mathrm{~cm}$. A peristaltic chemical metering pump was connected to the column and used to rinse media with $1 \mathrm{~L} \mathrm{DI}$ water. $1 \mathrm{ml}$ of $40 \mathrm{mg} / \mathrm{L}$ DB 26 solution was used for testing the removal efficiency of absorbents. The $\mathrm{pH}$ of the zeolites was adjusted to 7 with $0.1 \mathrm{M} \mathrm{NaOH}$ prior to the experiment using a flow rate of $5 \mathrm{ml} / \mathrm{min}$.

\section{Results and Discussion}

Gas sorption analysis was used to determine the extent in which the physical surficial features of the clean zeolite were modified by various acid treatments. 
As shown in Figure 1, the surface areas, pore volumes, and pore diameters of the materials provide the most useful insight into the features desired for the surface of the material. The hydrochloric acid treated sample showed the highest surface area at $276.5 \mathrm{~m}^{2} \cdot \mathrm{g}^{-1}$ followed by nitric, sulfuric, and acetic acid treated samples respectively. The acetic acid sample shows an even lower surface area than the untreated material, showing that nothing really changed in terms of ace area. All the acid treatments slightly reduce the pore volume, which nitric acid had the greatest impact although sulfuric acid made almost no impact to the pore volume. Pore sizes for hydrochloric, nitric, and sulfuric acid treatments were moderately reduced by approximately $10-13 \AA$, however acetic acid shows a dramatic increase with $92.464 \AA$.

These results show similar trends to other findings [14] [15]. The surface area of untreated clinoptilolite in one study was identical to the surface area of our untreated clinoptilolite [16]. The adsorption isotherms also show typical curves associated with these types of materials [17].

In the same study the effects of acid treatment with hydrochloric acid was examined yielding a significantly lower surface area. This is most likely attributed to variation in the method itself or the concentration of acid and would suggest that refluxing the zeolite in the acid is a crucial factor in the modification of the surface. Higher surface areas are found in ultra-stable Y type zeolites in both the untreated sample and their phosphoric/citric acid treated samples, however not much difference was observed between the two in this case in terms of surface area [11]. The results of this study compare to the results observed in the treatment with glacial acetic acid. The results for acetic acid would suggest that it had essentially no impact on modification of the zeolite. It would appear as though treatment with the acetic acid blocks more of the smaller pores, leaving only the larger pores available for adsorption. In a similar study where the impacts of hydrochloric and citric acids were observed on a synthetic ZSM-5 zeolite show that acid treatment at $363 \mathrm{~K}$ had very little impact on the surface area and pore volumes of the material [18]. The acid concentrations and temperature were very similar; the only notable differences are in the zeolite type and treatment times. This would suggest that this treatment method is selective to zeolite type in the interest of increasing surface area.

Data obtained from FTIR shown in Figure 2 is very similar to spectra obtained for clinoptilolite in other studies [19] [20]. The peak around $1050 \mathrm{~cm}^{-1}$ corresponds to $\mathrm{Si}-\mathrm{O}$ stretching where the hydrochloric acid treated material has the highest intensity after the clean zeolite. Another peak appears around $795 \mathrm{~cm}^{-1}$ and is indicative of $\mathrm{SiO}_{2}$ and $\mathrm{AlO}_{2}$ also showing an increased intensity for hydrochloric acid treated samples [21]. The increasing intensity for the Si-O band should be expected for a dealumination process and would suggest that the $\mathrm{Si} / \mathrm{Al}$ ratio has been increased. Further investigation would be necessary to confirm $\mathrm{Si} / \mathrm{Al}$ ratio; however, it appears that this would have been achieved in the case of hydrochloric acid treatment. An increased Si/Al ratio would be greatly 


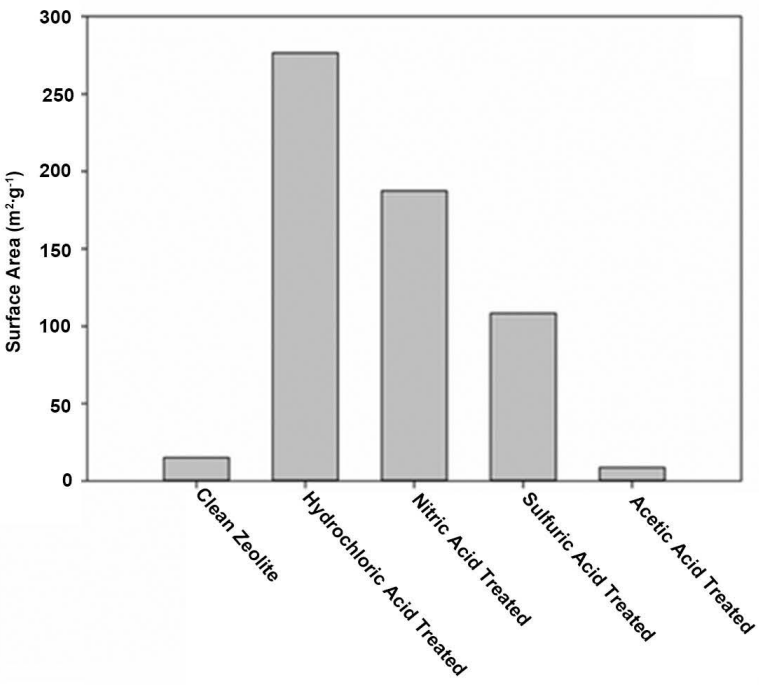

(A)
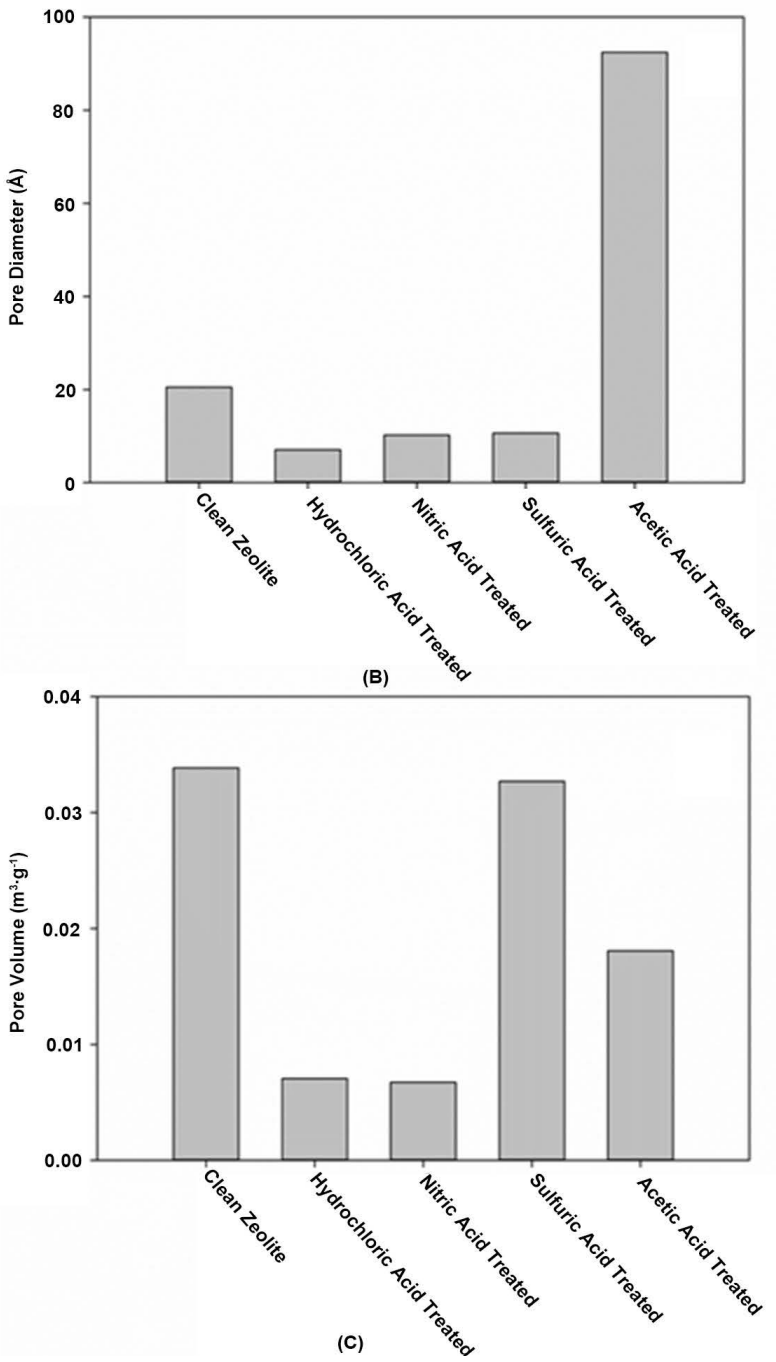

Figure 1. The data for the sample (A) surface area, (B) pore volume, and (C) pore diameter. Hydrochloric acid made the most significant modification to the physical features of the zeolite. 


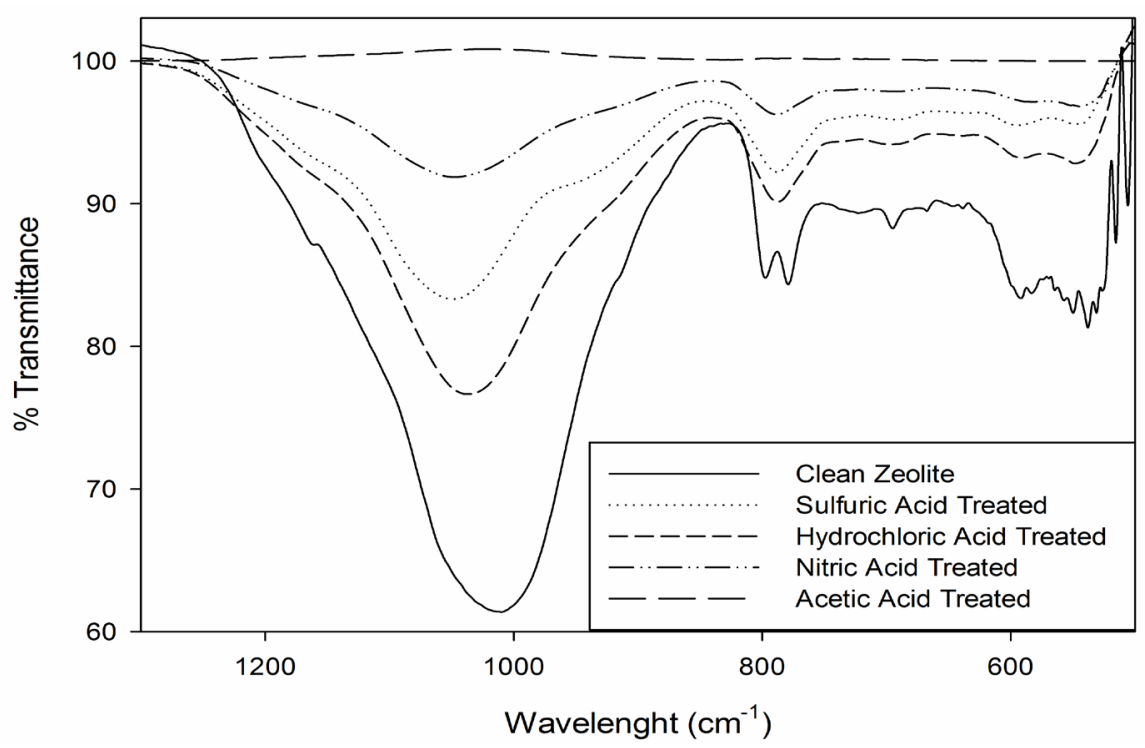

Figure 2. FTIR spectra of the untreated and acid treated samples between $500 \mathrm{~cm}^{-1}$ and $1300 \mathrm{~cm}^{-1}$. The Si-O peak is more intensified than the untreated material for all the strong acids.

desirable as it is associated with higher polarity and hydrophobicity, which in turn provides enhanced adsorption capabilities [2].

DTG was examined to determine the thermal stability of the samples after treatment with acid. The most stable samples within the temperature range examined were the clean zeolite and the acetic acid treated sample as shown in Figure 3. Out of the samples that made a significant impact on the zeolites surface area, the hydrochloric acid treated sample showed slightly higher stability at $600^{\circ} \mathrm{C}$ losing only $9.9 \%$ of its mass. However, there is essentially no significant change in the thermal stability of the acid treated zeolites and the untreated zeolite. The percentage of mass lost is mostly attributed to the loss of water from the pores at lower temperatures. These results are in close agreement with other findings in both the mass lost and the DTG curves [22] [23] [24] showing that the material retains its thermal stability after acid treatment.

XRD data was obtained to gain more insight to the structure of the zeolite. The data in Figure 4 show a slight shift at approximately $2 \theta=26.5^{\circ}$ towards smaller values for the acid treated samples and is characteristic for quartz and peaks at $22.3^{\circ}$ and $30^{\circ}$, which is characteristic of clinoptilolite [25]. Results showed that characteristic peak intensities of the clinoptilolite were almost same compared to the untreated zeolite after acetic acid treatment, indicating that crystal structure of zeolite remained stable. On the other hand, hydrochloric acid, sulfuric acid and nitric acid had higher impact on the crystallinity of the zeolites, from higher impact to lower impact, respectively. It is well known that adsorption is related to surface area and surface chemistry. It is expected that higher crystallinity lowers the porosity and surface area, leading to a surface with less defects, less energetic sites and lower adsorption properties. The peak intensity decreases at $22.5^{\circ}$ likely attributed to lamellar distortion causing partial 


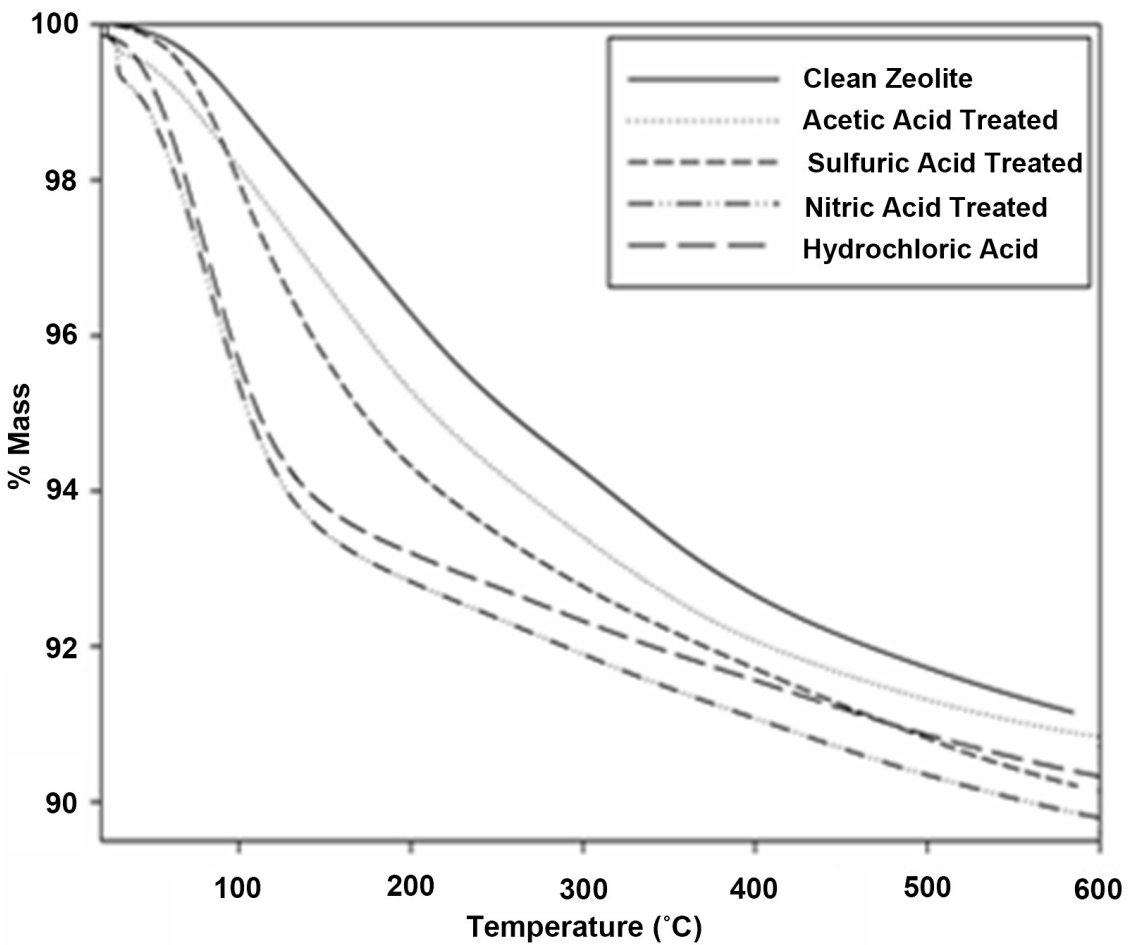

Figure 3. Results from DTG showing the percentage of the mass lost as the treated materials reach $600^{\circ} \mathrm{C}$. There is essentially no change in the thermal stability of the acid treated zeolite and the untreated zeolite.

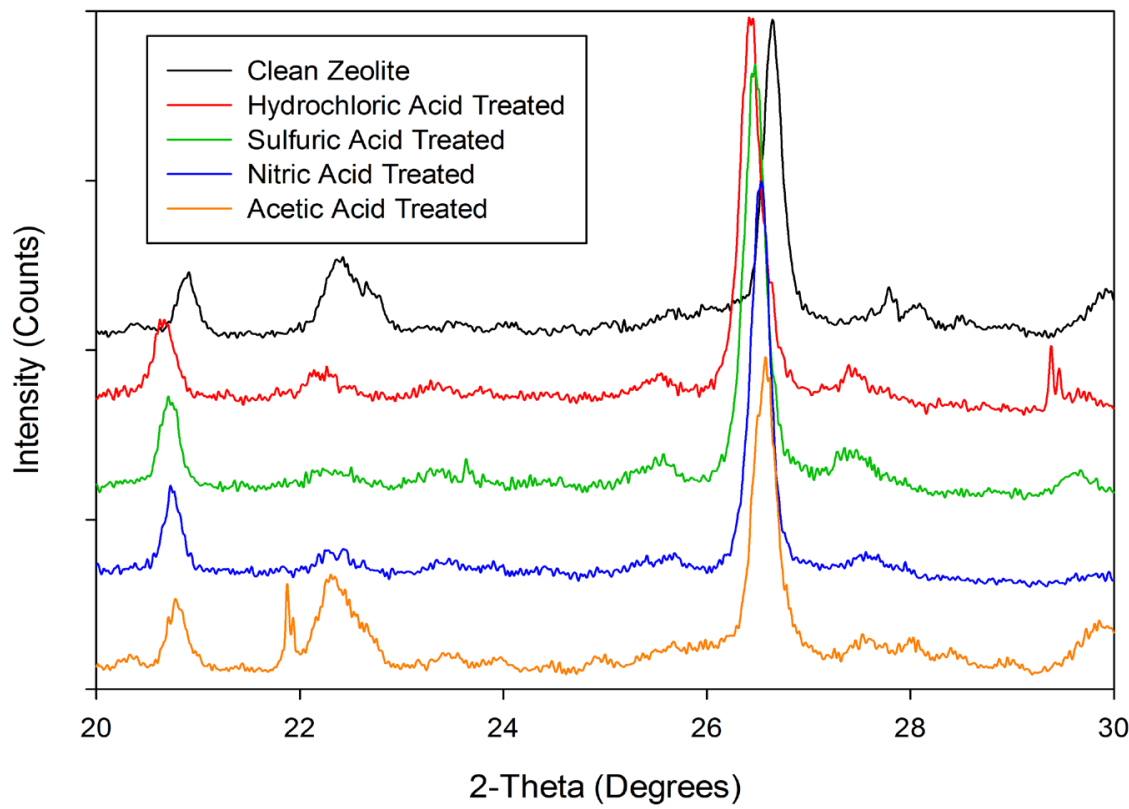

Figure 4. XRD patterns of zeolites. Clinoptilolites peaks at $22.3^{\circ}$ and $30^{\circ}$; quartz peak at $26.6^{\circ}$.

decomposition of the structure while the shifting is associated with a decrease in the interlayer region due to metals removed after acid leaching [26]. On the other hand, a significant change was observed in the quartz, mostly for hydrochloric 
acid, but also for sulfuric and nitric acid. This is expected as certain acids, like hydrochloric acid, which is widely known by its purification properties of quartz.

Images acquired from SEM in Figure 5 provide information about the surface morphology of the particles. Figure 5(A) and Figure 5(B) show non-treated zeolite particles at slightly different magnifications. The typical elongated features of zeolite can be observed as well as some of the smaller, hexagonal crystals. Acetic acid treated particles in Figure 5(C) have similar morphology of the untreated particles. While particles treated with nitric acid (Figure 5(D)), hydrochloric acid (Figure 5(E)), sulfuric acid (Figure 5(F)) also have elongated features, they appear to differ on the predominant morphology of the smaller particles. Hydrochloric acid treated particles appear to have more predominant random-shaped smaller particles, while both sulfuric and nitric acid treated particles appear to have predominantly hexagonal crystals.

The results indicate that there was no significant modification to the clean zeolite using the glacial acetic acid, however sulfuric, nitric, and hydrochloric acids show substantial surface modification. All the samples were able to retain most of their thermal stability with minimal reduction of mass loss at higher temperatures around $600^{\circ} \mathrm{C}$. Other studies as previously mentioned also show that other weak acids have a minimal effect on the material as well [14]. The mechanism for dealumination of zeolite using a strong acid has been studied and explained to be primarily due to electrostatic interactions, but also include dispersion forces throughout the reaction [8]. The negligible impact of the weak acids may indicate a preferable acid type for zeolite tailoring. However, it is not within the capability of this study to explain the influence of acid strength on zeolite modification based solely on five acids. In order to make any assumptions about this, not only would all the strong acids need to be tested, but a substantial number of weak acids over a greater range of $\mathrm{pKa}$ values.

Further investigation into other weak acids would need to be performed in order to confirm this assumption as well as additional investigation into the mechanisms for which weak acids make any notable modifications. Examining other various types of zeolite to correlate any preference of this acid treatment to a specific type would also provide useful information.

The shape of the breakthrough curves evolved systematically over the period that the DB26 pack was diffusing. Both untreated zeolite and acetic treated particle became more peaked at pore volume (PV) 5, whereas hydrochloric, sulfuric and nitric acid treated particles became more peaked at PV 4 and had fewer tailing effects as the dye pack thinned (Figure 6(A)). Removal efficiency experiments (Figure 6(B)) indicated that the sulfuric acid treated sample achieved the best removal of DB 26 (57.27\%), nearly three times higher than the untreated zeolite (19.06\%). On the other hand, acetic acid treated sample yielded the lowest removal (17.76\%). The nitric acid treated zeolite and hydrochloric acid treated zeolite show little improvementin adsorption capacity when compared with the clean zeolite (19.46\% and 22.48\%, respectively). Even though hydrochloric 


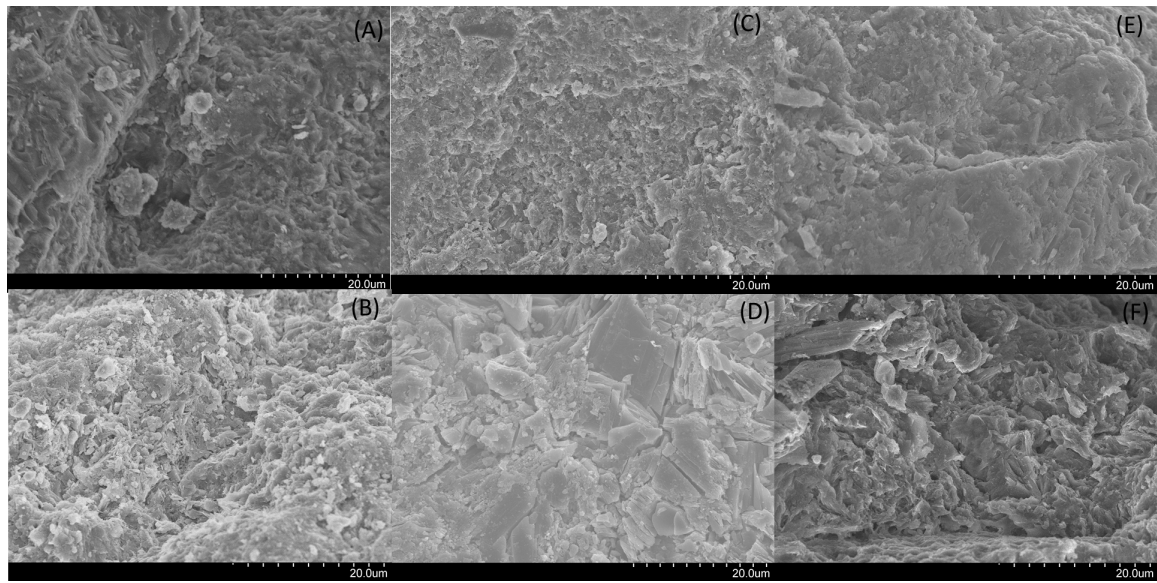

Figure 5. Surface morphology of the clinoptilolite zeolite particles using SEM of (A) untreated zeolite at $2000 \times$ and (B) $2500 \times$ magnifications; (C) acetic acid treated zeolite at $2000 \times$, (C) hydrochloric acid treated zeolite at 2500×; (D) nitric acid treated zeolite at 2200×; (E) sulfuric acid treated zeolite at $2500 \times$ magnifications.

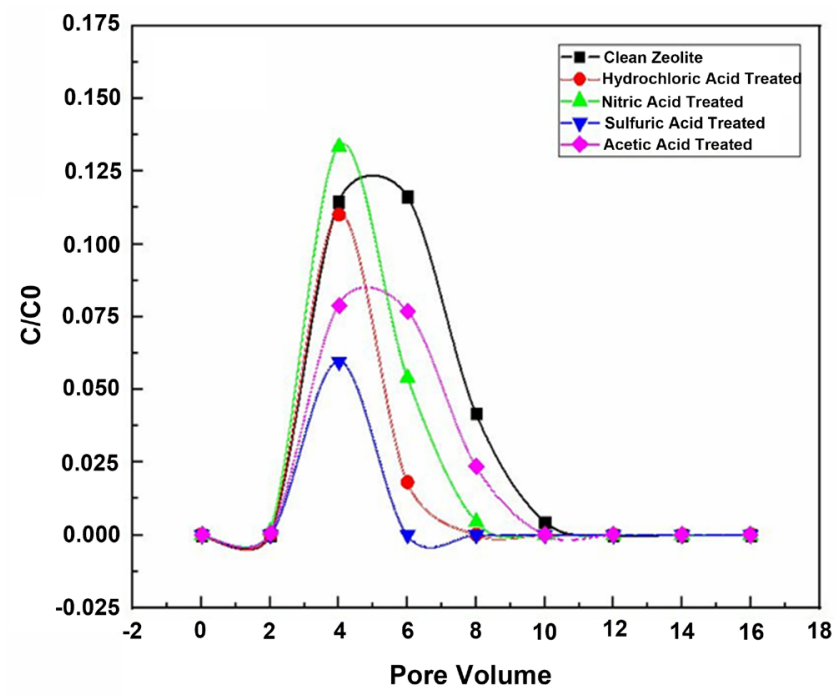

(A)

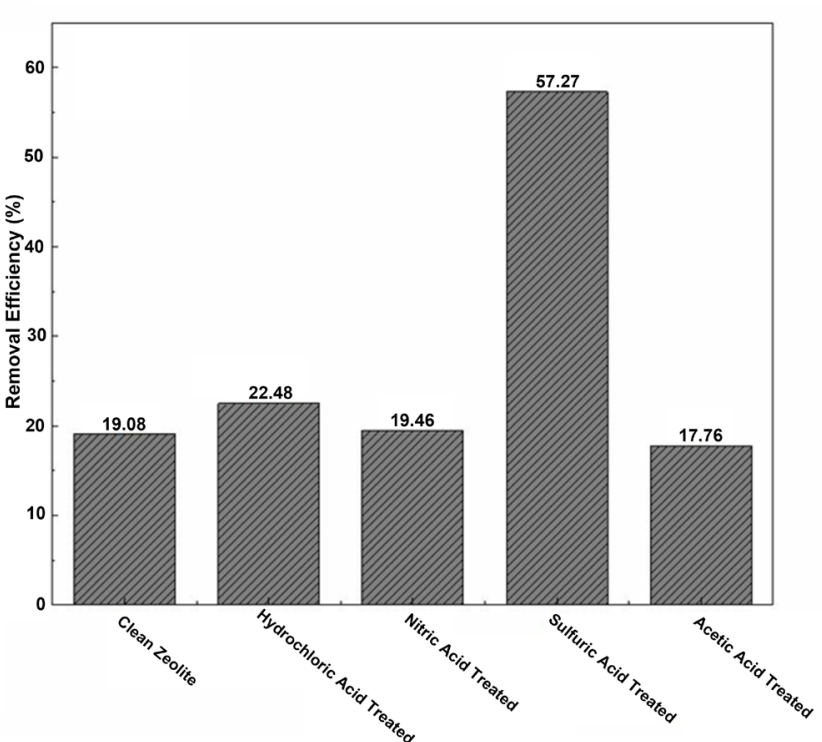

(B)

Figure 6. (A) Breakthrough curve for sorption of DB26 in column mode experiment (B) Removal efficiency of the zeolite particles when column experiments are spiked with $1 \mathrm{ml}$ of $40 \mathrm{mg} / \mathrm{L} \mathrm{DB} 26$ solution.

acid treated particles have higher surface area, they also have higher crystallinity which could explain reduced adsorption properties when compared to sulfuric acid treated particles. This however only explains adsorption characteristics of the particles for weakly cationic model compound DB26 at neutral pH values. In order to fully understand the materials adsorption capabilities, further testing would need to be done adjusting some of these parameters.

\section{Conclusion}

Our data indicate that hydrochloric acid has the greatest impact on the modifi- 
cation of the material in terms of surface area, pore size, and chemical surface composition. Both nitric and sulfuric acids also made a significant contribution to the zeolite's modification; however glacial acetic acid made practically no change to the samples' surface, further confirmed by XRD and SEM. On the other hand, the adsorption behavior of sulfuric acid treated particles is superior when compared to the other particles for removal of a model compound DB26 in a column-based experiment, reaching nearly three times higher removal than the untreated zeolite, as well as the other acid treated particles. Comparing our results with what others have found in previous studies it suggests that experimental conditions such as temperature, acid concentration, and length of zeolite treatment play an important role to the extent in which the material is modified. The data from FTIR suggest that the hydrochloric acid treatment was able to increase the $\mathrm{Si} / \mathrm{Al}$ ratio which is associated with higher hydrophobicity and polarity. Further evaluation would be needed to confirm increased hydrophobicity and polarity of the zeolite, which in this case is desirable because of its association with higher adsorption. The ability of tailoring natural zeolites via acid treatments to acquire specific adsorption properties facilitates the adaptability of these particles for broader applications in fields like industrial air or water filtration and catalysis.

\section{Acknowledgements}

We thank the support for Undergraduate Research Fellows (SURF) program at the University of Wisconsin-Milwaukee (UWM) for partially funding this research.

\section{Conflicts of Interest}

The authors declare no conflicts of interest regarding the publication of this paper.

\section{References}

[1] Koshy, N. and Singh, D.N. (2016) Fly Ash Zeolites for Water Treatment Applications. Journal of Environmental Chemical Engineering, 4, 1460-1472. https://doi.org/10.1016/j.jece.2016.02.002

[2] Mohau Moshoeshoe, M.S.N.-T. and Obuseng, V. (2017) A Review of the Chemistry, Structure, Properties and Applications of Zeolites. American Journal of Materials Science, 7, 196-221.

[3] Wang, S.B. and Peng, Y.L. (2010) Natural Zeolites as Effective Adsorbents in Water and Wastewater Treatment. Chemical Engineering Journal, 156, 11-24. https://doi.org/10.1016/j.cej.2009.10.029

[4] Widiastuti, N., et al. (2008) The Potential Application of Natural Zeolite for Greywater Treatment. Desalination, 218, 271-280. https://doi.org/10.1016/j.desal.2007.02.022

[5] Adinehvand, J., Shokuhi Rad, A. and Tehrani, A.S. (2016) Acid-Treated Zeolite (Clinoptilolite) and Its Potential to Zinc Removal from Water Sample. International Journal of Environmental Science and Technology, 13, 2705-2712. 
https://doi.org/10.1007/s13762-016-1105-1

[6] Ates, A. and Hardacre, C. (2012) The Effect of Various Treatment Conditions on Natural Zeolites: Ion Exchange, Acidic, Thermal and Steam Treatments. Journal of Colloid and Interface Science, 372, 130-140. https://doi.org/10.1016/j.jcis.2012.01.017

[7] Rivera, A., et al. (2013) Natural and Sodium Clinoptilolites Submitted to Acid Treatments: Experimental and Theoretical Studies. The Journal of Physical Chemistry $C, 117,4079-4088$. https://doi.org/10.1021/jp3115447

[8] Valdiviés-Cruz, K., Lam, A. and Zicovich-Wilson, C.M. (2017) Full Mechanism of Zeolite Dealumination in Aqueous Strong Acid Medium: Ab Initio Periodic Study on H-Clinoptilolite. The Journal of Physical Chemistry C, 121, 2652-2660.

https://doi.org/10.1021/acs.jpcc.6b09794

[9] Pandaa, A.K., Mishra, B.G., Mishra, D.K. and Singh, R.K. (2010) Effect of Sulphuric Acid Treatment on the Physio-Chemical Characteristics of Kaolin Clay. Colloids and Surfaces A: Physiochemical Engineering Aspects, 363, 98-104.

[10] Apelian, M.R., et al. (1996) Dealumination of Zeolite $\beta$ via Dicarboxylic Acid Treatment. The Journal of Physical Chemistry, 100, 16577-16583.

https://doi.org/10.1021/jp960376s

[11] Li, X., et al. (2014) Combined Modification of Ultra-Stable Y Zeolites via Citric Acid and Phosphoric Acid. Applied Petrochemical Research, 4, 343-349. https://doi.org/10.1007/s13203-014-0070-1

[12] Matias, P., et al. (2009) Effect of Dealumination by Acid Treatment of a HMCM-22 Zeolite on the Acidity and Activity of the Pore Systems. Applied Catalysis A: General, 365, 207-213. https://doi.org/10.1016/j.apcata.2009.06.014

[13] Lutz, W. (2014) Zeolite Y: Synthesis, Modification, and Properties-A Case Revisited. Advances in Materials Science and Engineering, 2014, Article ID: 724248.

[14] Burris, L.E. and Juenger, M.C.G. (2016) The Effect of Acid Treatment on the Reactivity of Natural Zeolites Used as Supplementary Cementitious Materials. Cement and Concrete Research, 79, 185-193.

https://doi.org/10.1016/j.cemconres.2015.08.007

[15] Plana-Pallejà, J., et al. (2016) Effect of Zeolite Acidity and Mesoporosity on the Activity of Fischer-Tropsch Fe/ZSM-5 Bifunctional Catalysts. Applied Catalysis A: General, 515, 126-135. https://doi.org/10.1016/j.apcata.2016.02.004

[16] Sprynskyy, M., et al. (2006) Study of the Selection Mechanism of Heavy Metal ( $\mathrm{Pb}^{2+}$, $\mathrm{Cu}^{2+}, \mathrm{Ni}^{2+}$, and $\mathrm{Cd}^{2+}$ ) Adsorption on Clinoptilolite. Journal of Colloid and Interface Science, 304, 21-28. https://doi.org/10.1016/j.jcis.2006.07.068

[17] Sing, K.S.W. and Williams, R.T. (2004) Physisorption Hysteresis Loops and the Characterization of Nanoporous Materials. Adsorption Science \& Technology, 22, 773-782. https://doi.org/10.1260/0263617053499032

[18] Fan, Y., et al. (2006) Acidity Adjustment of HZSM-5 Zeolites by Dealumination and Realumination with Steaming and Citric Acid Treatments. The Journal of Physical Chemistry B, 110, 15411-15416. https://doi.org/10.1021/jp0607566

[19] Favvas, E.P., et al. (2016) Clinoptilolite, a Natural Zeolite Material: Structural Characterization and Performance Evaluation on Its Dehydration Properties of Hydrocarbon-Based Fuels. Microporous and Mesoporous Materials, 225, 385-391. https://doi.org/10.1016/j.micromeso.2016.01.021

[20] Baghbanian, S.M., Rezaei, N. and Tashakkorian, H. (2013) Nanozeolite Clinoptilolite as a Highly Efficient Heterogeneous Catalyst for the Synthesis of Various 
2-Amino-4H-Chromene Derivatives in Aqueous Media. Green Chemistry, 15, 3446-3458. https://doi.org/10.1039/c3gc41302k

[21] Coloma, A., et al. (2014) Development of an Active Film with Natural Zeolite as Ethylene Scavenger. Journal of the Chilean Chemical Society, 59, 2409-2414.

https://doi.org/10.4067/S0717-97072014000200003

[22] Vasylechko, V.O., et al. (1999) Adsorption of Copper on Transcarpathian Clinoptilolite. Adsorption Science \& Technology, 17, 125-134. https://doi.org/10.1177/026361749901700206

[23] Vasylechko, V.O., et al. (2015) A Solid-Phase Extraction Method Using Transcarpathian Clinoptilolite for Preconcentration of Trace Amounts of Terbium in Water Samples. Chemistry Central Journal, 9, 45-45. https://doi.org/10.1186/s13065-015-0118-z

[24] Rakitskaya, T.L., et al. (2017) Acid-Modified Clinoptilolite as a Support for Palladium-Copper Complexes Catalyzing Carbon Monoxide Oxidation with Air Oxygen. Chemistry Central Journal, 11, 28. https://doi.org/10.1186/s13065-017-0256-6

[25] Tsiuri Ramishvili, V.T., Chedia, R., Sanaia, E., Gabunia, V. and Kokiashvili, N. (2017) Preparation of Ultradispersed Crystallites of Modified Natural Clinoptilolite with the Use of Ultrasound and Its Application as a Catalyst in the Synthesis of Methyl Salicylate. American Journal of Nano Research and Applications, 5, 26-32.

[26] Bieseki, L., et al. (2013) Acid Treatments of Montmorillonite-Rich Clay for Fe Removal Using a Factorial Design Method. Materials Research, 16, 1122-1127. https://doi.org/10.1590/S1516-14392013005000114 